\title{
EVALUASI KESESUAIAN DI AREAL PENGGUNAAN LAIN UNTUK TANAMAN GAMBIR (Uncaria gambier Roxb.) DI KECAMATAN SALAK KABUPATEN PAK-PAK BHARAT
}

\section{Evaluation of Other Use Areas for Gambir Plant (Uncaria gambier Roxb.) in Salak District, Pak-Pak Bharat Regency}

\author{
Fitra Syawal Harahap ${ }^{1 *}$, Abdul Rauf ${ }^{2}$, Deni Elfiati ${ }^{3}$, Sarifuddin ${ }^{2}$, \\ Simon Haholongan Sidabuke ${ }^{4}$ \\ ${ }^{1}$ Sekolah Tinggi Pertanian (STIPER) Labuhan Batu Sumatera Utara 21418 \\ 2 Program Studi Agroteknologi Fakultas Pertanian Universitas Sumatera Utara 20222 \\ ${ }^{3}$ Fakultas Kehutanan Universitas Sumatera Utara 20222 \\ ${ }^{4}$ Program Studi Manajemen Kehutanan Fakultas Pertanian Universitas Simalungun 21142 \\ *Penulis korespondensi : fitrasyawalharahap@gmail.com
}

\begin{abstract}
Salak Sub-district has a land area use covering an area of 3607.20 ha or $13.67 \%$ of the total area of 25640.99 ha Pakpak Bharat so that other land area use (APL) in Salak Sub-district needs to be supported with information on land suitability so that the potential of very large land can be utilized in agricultural cultivation activities, with the expectation that productivity can improve the welfare of local people who mostly work as farmers. The purpose of this research is to know and evaluate the characteristics of the actual land suitability level and the suitability of potential land in Salak Subdistrict so that it is known that suitable land conditions for agricultural commodities will be developed to increase crop Gambir (Uncaria gambir Roxb.) productivity. The research method used survey method. Unit of land based on soil maps, maps of slope, elevation maps, land cover maps, and consists of 8 units of land and 18 sampling points. Research data were analyzed using matching method. Research results Limiting factor and improvement effort of plant commodity of Gambir Plant (Uncaria gambir Roxb.) Rooting factor (rc) and nutrient retention (nr). Improvement efforts that can be done by making drainage and calcification $\mathrm{CaCO}_{3}$,
\end{abstract}

Keywords: gambir cropland suitability, land area use, land evaluation, Salak District

\section{Pendahuluan}

Kecamatan Salak memiliki luas lahan Areal Penggunaan Lain (APL) seluas 3.607,20 ha atau 13,67 \% dari 25.640,99 ha total luas APL keseluruhan di Kabupaten Pakpak Bharat (Pemkab Pakpak Bharat, 2014). Dengan luas lahan APL yang cukup luas di kecamatan tersebut tentunya sangat besar potensi lahan untuk dimanfaatkan dalam kegiatan budidaya pertanian, dengan harapan produktivitas tersebut dapat meningkatkan kesejahteraan masyarakat setempat yang sebagian besar berprofesi sebagai petani. Pembukaan areal baru perlu diteliti sumberdaya lahannya guna menentukan kesesuaian lahan untuk penggunaan tertentu, agar lahan tersebut dapat produktif secara berkelanjutan (Djomantara and Rachamawati., 2000). Pemilihan lahan yang sesuai membutuhkan metode dan cara evaluasi kesesuaian lahan yang lebih aktual dan lebih dapat diandalkan, sebagai pedoman dalam upaya pengelolaan lahan untuk dapat mencapai produktifitas normal (Hutapea 1991). Gambir (Uncaria gambier Roxb.) merupakan salah satu komoditi perkebunan yang memiliki nilai ekonomi yang cukup tinggi serta memiliki prospek yang baik bagi petani maupun sebagai 


\section{Jurnal Tanah dan Sumberdaya Lahan Vol 7 No 1 : 7-14, 2020 \\ e-ISSN:2549-9793, doi: 10.21776/ub.jts1.2020.007.1.2}

pemasok devisa negara. Indonesia menjadi salah satu negara pemasok utama kebutuhan gambir dunia. Menurut data dari BPTP Sumatera Utara (2006).

Di Indonesia umumnya gambir digunakan untuk menyirih. Kegunaan lain dari gambir adalah sebagai bahan baku dalam industri farmasi, industri kosmetik, industri batik, industri cat, industri penyamak kulit, biopestisida, hormon pertumbuhan, pigmen, dan sebagai campuran bahan pelengkap makanan (Elida, 2011). Dengan semakin berkembangnya jenis industri yang memerlukan bahan baku gambir, maka dapat diperkirakan bahwa tanaman gambir mempunyai prospek masa depan yang cerah. Kabupaten Pakpak Bharat merupakan hasil pemekaran dari kabupaten Dairi di Propinsi Sumatera Utara.

Secara geografis, kabupaten Pakpak Bharat terletak diantara koordinat 02 15 '49" -

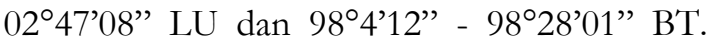
Kabupaten ini umumnya berada pada ketinggian rata-rata antara 250-1.400 meter di atas permukaan laut, memiliki keadaan lereng yang bervariasi yaitu mulai dari datar, berombak, bergelombang, curam hingga terjal. Suhu udara berkisar antara $18^{\circ} \mathrm{C}$ Sampai $28^{\circ} \mathrm{C}$ dengan curah hujan sekitar $3161 \mathrm{~mm} /$ tahun. Kabupaten Pakpak Bharat merupakan salah satu daerah penghasil gambir di Sumatera Utara dan merupakan komoditi unggulan disamping nilam, kemenyan dan kopi.

Berdasarkan data dari Dinas Pertanian dan Perkebunan Kabupaten Pakpak Bharat (2012) produksi gambir di Kabupaten Pakpak Bharat sebesar 1.523 ton dengan luas areal tanaman produktif sebesar 909 hektar. Keseluruhan dari areal tersebut merupakan perkebunan rakyat dimana sebagian besar bahkan hampir seluruhnya dikembangkan di lahan perbukitan dan lahan miring serta dengan teknik pengelolaan yang sangat sederhana yang akibatnya dapat membuat produktifitas dan mutu dari gambir menjadi rendah, sehingga berakibat pada nilai jual yang lebih rendah. Menurut Mukhlis (2007) banyaknya unsur hara atau kapur yang harus diberikan ke sistem tanah tanaman dapat ditentukan secara tepat dengan mengetahui tingkat kesuburan suatu tanah, yang dapat dilakukan dengan cara evaluasi tanah. Untuk mengukur tingkat kesesuaian lahan untuk tanaman gambir dilakukan dengan cara membandingkan karakteristik lahan yang ada di lapangan, dengan tataran idealnya yaitu (S1) sesuai, (S2) agak sesuai dan (S3) tidak sesuai (Hermon and Khairani, 2009).

Sesuai dengan kebijaksaan Pemerintah Daerah di tahun mendatang, Pakpak Bharat akan menjadi penghasil gambir terbesar melalui Program sejuta Gambir (Uncaria gambier Roxb.). Namun informasi mengenai ketersediaan lahan Gambir untuk pengembangan ke depan masih sangat terbatas. Oleh sebab pada tahun 2006, Pemerintahaan Kabupaten Pakpak Bharat bekerjasama BPTP Sum.Utara melakukan pengkajian kesesuaian lahan untuk tanaman Gambir di Kabupaten Pakpak Bharat.

Berdasarkan hal itu maka perlu dilakukan evaluasi kesesuaian lahan di Kecamatan Salak, sehingga akan dapat diketahui tentang gambaran keadaan hara di dalam tanah yang nantinya dapat digunakan untuk menentukan tindakan pengelolan yang harus dilakukan agar tanaman gambir tumbuh dengan baik dan dapat menghasilkan produksi secara optimum. Tujuan penelitian ini adalah untuk mengetahui dan mengevaluasi karakteristik tingkat kesesuaian lahan aktual dan kesesuaian lahan potensial di Kecamatan Salak sehingga diketahui kondisi lahan yang sesuai untuk komoditi pertanian yang akan dikembangkan lahan untuk meningkatkan produktivitas tanaman Gambir (Uncaria gambier Roxb.)

\section{Metode Penelitian}

Kecamatan Salak secara administratif merupakan bagian dari Kabupaten Pakpak Bharat, yang berbatasan dengan beberapa Kecamatan dan Kabupaten dengan batas-batas sebagai berikut: Sebelah Utara: Kecamatan Tinada dan Kecamatan Siempat Rube; Sebelah Timur: Kecamatan Sitellu Tali Urang Julu dan Kecamatan Siempat Rube; Sebelah Selatan: Kabupaten Humbang Hasundutan; Sebelah Barat: Kecamatan Pergetteng-getteng Sengkut.

Wilayah Kecamatan Salak memiliki luas $245,57 \mathrm{~km}^{2}$, terdapat areal pertanian persawahan sekitar 2,43 $\mathrm{km}^{2}$, areal pertanian non persawahan sekitar 46,52 $\mathrm{km}^{2}$, areal perkampungan sekitar $4,88 \mathrm{~km}^{2}$, sedangkan sisanya areal hutan sekitar 191,74 $\mathrm{km}^{2}$. Kecamatan Salak merupakan daerah berbukit- 
bukit, berada pada ketinggian 700-1200 m dpl dengan kemiringan lereng 0-250, memiliki curah hujan rata-rata $2920 \mathrm{~mm} /$ tahun, temperatur rata-rata tahunan $19,64 \circ \mathrm{C}$ dan kelembaban 83,28 \% (Data dari Pemkab. Pakpak Bharat).

Penelitian dilakukan menggunakan metode survei yang terdiri dari 5 tahap yaitu persiapan, pra-survei, survei utama, analisis tanah di Laboratorium serta pengolahan data. Pengambilan sampel tanah dilakukan dengan cara pemboran pada areal satuan lahan. Satuan lahan dipilih berdasarkan peta satuan unit penggunaan lahan. Berdasarkan penggunaan peta, terdapat sebanyak 6 titik sampel setelah dikompositkan (Gambar 1). Penentuan nilai karakteristik lahan untuk sampel tanah dilakukan dengan menggunakan bor tanah pada kedalaman 0-30 cm, dan 30-60 cm. Penentuan sifat kimia tanah dilakukan dengan analisis tanah di Laboratorium Riset dan Teknolgi Fakultas Pertanian USU Medan.

Data penelitian yang diperoleh diinterpretasikan ke dalam kriteria tingkat kesuburan tanah kelas kesesuaian lahan menurut Sys et al. (1993) dan Puslittan (1995). Proses evaluasi lahan ditentukan dengan cara matching (mencocokkan) antara karakteristik lahan dengan persyaratan tumbuh tanaman durian, yang diformulasikan dalam petunjuk teknis evaluasi lahan untuk komoditas pertanian (Hardjowigeno, 2003; Ritung et al., 2011). Pada proses matching digunakan hukum minimum Leibig untuk menentukan faktor pembatas yang akan mempengaruhi kelas dan subkelas kesesuaian lahannya. Hasil kesesuaian lahan komoditi tanaman ditampilkan dalam bentuk tabel kesesuaian lahan aktual dan potensial menggunakan perangkat lunak GIS dan dipetakan kesesuaian lahan aktual dan kesesuian lahan potensialnya.

\section{Hasil dan Pembahasan}

\section{Karakteristik lahan di Kecamatan Salak}

Karakteristik lahan di Areal Penggunaan Lain (APL) di Kecamatan Salak, yang sebelumnya merupakan kawasan hutan dan lahan pertanian. Hasil survei lapangan dan analisis contoh tanah di laboratorium disajikan pada Tabel 1. Dari Tabel 1 dapat diketahui, bahwa lokasi pengamatan dan pengambilan sampel tanah tersebut dapat dikelompokkan ke dalam 8 (delapan) unit lahan (land unit), dengan karakteristik lahan untuk kedalaman 0-30 masing-masing disajikan pada Tabel 1. Jenis tanah yang terdapat di lahan APL inididominasi Andisol dan terdapat juga jenis tanah inseptisol. Jenis tanah Andisol dengan greatgroup Hapludands dominan pada pertanian lahan kering. Hapludands adalah tanah yang terbentuk dari bahan induk abu vulkanis. Berdasarkan klasifikasi iklim Oldeman (1975) daerah ini termasuk ke dalam zone iklim (D1) zone iklim yang mempunyai karakteristik 3-4 bulan basa dan $<2$ bulan kering secara berturut-turut. Zona agroekosistem yang didominasi pertanian lahan kering dan kawasan hutan dengan bentuk wilayah berbukit, mempunyai kemiringan lereng 2-73 \%. Karakteristik fisik tanah yang mempengaruhi perakaran tanaman seperti tekstur, drainase dan kedalaman perakaran termasuk cukup baik yaitu drainase tanah baik, tekstur pasir berlempung, lempung berpasir, lempung liat berpasir, serta kedalaman efektif hingga $>100 \mathrm{~cm}$.

\section{Kesesuaian lahan untuk tanaman Gambir (Uncaria gambier Roxb.)}

Pada Tabel 2 Kesesuaian lahan untuk tanaman Gambir (Uncaria gambier Roxb.), faktor-faktor pembatas kesesuaian lahan untuk tanaman gambir yang harus diperbaiki untuk unit lahan 1 sampai 8 adalah, ketersediaan air dan retensi hara kejenuhan basa. Faktor pembatas curah hujan tahunan yang tinggi dapat dilakukan pengelolaan tata air dengan pembuatan saluran drainase untuk meningkatkan kelas kesesuaian menjadi $\left(\mathrm{S}_{1}\right)$. Faktor pembatas tekstur tanah tidak dapat dilakukan usaha perbaikan,sehingga tetap sesuai marginal $\left(\mathrm{S}_{3}\right)$. Tekstur tanh tidak dapat dilakukan usaha perbaikan karena tekstur tanah tidak akan berubah dalam waktu yang singkat. Usaha perbaikan yang dapat dilakukan untuk meningkatkan kelas kesesuaian retensi hara kejenuhan basa menjadi cukup sesuai $\left(\mathrm{S}_{2}\right)$ adalah pemberian $\mathrm{CaCO}_{3}$ sebanyak 4,14 t ha-1. Untuk memperoleh kejenuhan basah menjadi 35\% diperlukan 4,2 me Ca $100 \mathrm{~g}^{-1}$. Dari hasil analisis GIS, diperoleh luas kesesuaian lahan aktual dan potensial pada areal penggunaan lain di Kecamatan Salak, untuk tanaman Gambir (Tabel 3) dan peta kesesuaian lahannya disajikan pada Gambar 3 dan 4. 
Jurnal Tanah dan Sumberdaya Lahan Vol 7 No 1 : 7-14, 2020

e-ISSN:2549-9793, doi: 10.21776/ub.jts1.2020.007.1.2

Tabel 1. Karakteristik lahan untuk Unit Lahan 1-8 pada kedalaman 0-30 cm di areal penggunaan lain di Kecamatan Salak Kabupaten Pakpak Bharat untuk Evaluasi Kesesuaian Lahan Pertanian.

\begin{tabular}{|c|c|c|c|c|c|c|c|c|}
\hline \multirow{2}{*}{$\begin{array}{l}\text { Karakteristik } \\
\text { Lahan }\end{array}$} & \multicolumn{8}{|c|}{ Unit Lahan } \\
\hline & 1 & 2 & 3 & 4 & 5 & 6 & 7 & 8 \\
\hline \multicolumn{9}{|l|}{ Temperatur /tc } \\
\hline Temperaturrerata $\left({ }^{\circ} \mathrm{C}\right)$ & 20 & 20 & 19 & 19 & 21 & 19 & 18 & 21 \\
\hline Ketinggian tempat (mdpl) & 1024 & 969 & 1139 & 1269 & 965 & 1229 & 1379 & 863 \\
\hline \multicolumn{9}{|l|}{ Ketersediaan air /wa } \\
\hline Curah Hujan(mm) & 2920 & 2920 & 2920 & 2920 & 2920 & 2920 & 2920 & 2920 \\
\hline Lama Bulan Kering & 1 & 1 & 1 & 1 & 1 & 1 & 1 & 1 \\
\hline Zone Agroklimat & D1 & D1 & D1 & D1 & D1 & D1 & D1 & D1 \\
\hline Kelembaban(\%) & 83,28 & 83,28 & 83,28 & 83,28 & 83,28 & 83,28 & 83,28 & 83,28 \\
\hline \multicolumn{9}{|l|}{ Ketersediaan oksigen/oa } \\
\hline Drainase & Baik & Baik & Baik & baik & Baik & baik & Baik & baik \\
\hline \multicolumn{9}{|l|}{ Media perakaran /rc } \\
\hline Tekstur & $\begin{array}{c}\text { Pasir } \\
\text { Berlempuno }\end{array}$ & Lempung & Lempung & Lempung & Lempung & $\begin{array}{l}\text { Lempung } \\
\text { Bernasir }\end{array}$ & Lempung & Lempung Liat \\
\hline Bahan Kasar(\%) & 6,53 & 8,15 & 4,88 & 5,35 & $\begin{array}{l}\text { Derpasit } \\
8,76\end{array}$ & 5,88 & 7,35 & $\begin{array}{l}4,97 \\
4\end{array}$ \\
\hline Kedalaman Tanah(cm) & $>100$ & $>100$ & $>100$ & $>100$ & $>100$ & $>100$ & $>100$ & $>100$ \\
\hline \multicolumn{9}{|l|}{ Retensi hara/nr } \\
\hline KTK liat (cmol) & 26,40 & 26,06 & 44,64 & 39,96 & 23,88 & 49,56 & 21,84 & 25,56 \\
\hline Kejenuhan basa (\%) & 16,87 & 19,16 & 12,49 & 15,03 & 21,42 & 13,36 & 24,24 & 20,84 \\
\hline $\mathrm{pH} \mathrm{H} \mathrm{H}_{2} \mathrm{O}$ & 6,16 & 5,83 & 5,85 & 5,82 & 5,50 & 5,23 & 5,42 & 6,10 \\
\hline C-organik (\%) & 0,56 & 0,88 & 1,00 & 0,73 & 1,00 & 1,34 & 0,71 & 0,41 \\
\hline \multicolumn{9}{|l|}{ Ketersediaan Hara / na } \\
\hline N-total $(\%)$ & 1,14 & 0,29 & 0,36 & 0,46 & 0,41 & 0,51 & 0,55 & 0,06 \\
\hline P2O5 Bray II (ppm) & 5,81 & 23,66 & 7,09 & 6,74 & 11,40 & 8,49 & 6,51 & 33,90 \\
\hline K-tukar (mg/100g) & 1,544 & 1,263 & 1,676 & 0,987 & 1,649 & 1,894 & 0,947 & 0,672 \\
\hline \multicolumn{9}{|l|}{ Sodisitas / $\mathrm{xn}$} \\
\hline Alkalinitas/ESP (\%) & 1,00 & 1,90 & 1,23 & 1,48 & 1,91 & 1,16 & 2,12 & 1,83 \\
\hline Bahaya erosi / eh & & & & & & & & \\
\hline
\end{tabular}

http://jtsl.ub.ac.id 
Jurnal Tanah dan Sumberdaya Lahan Vol 7 No 1 : 7-14, 2020

e-ISSN:2549-9793, doi: 10.21776/ub.jts1.2020.007.1.2

\begin{tabular}{|c|c|c|c|c|c|c|c|c|}
\hline \multirow{2}{*}{$\begin{array}{l}\text { Karakteristik } \\
\text { Lahan }\end{array}$} & \multicolumn{8}{|c|}{ Unit Lahan } \\
\hline & 1 & 2 & 3 & 4 & 5 & 6 & 7 & 8 \\
\hline $\begin{array}{l}\text { Lereng }(\%) \\
\text { Bahaya Erosi }\end{array}$ & 22,8 & 12,4 & 23,3 & 74,2 & 7,5 & 27,0 & 43,6 & 2,5 \\
\hline $\begin{array}{l}\text { Bahaya banjir/fh } \\
\text { Genangan }\end{array}$ & F0 & F0 & $\mathrm{F} 0$ & F0 & F0 & F0 & F0 & F0 \\
\hline $\begin{array}{l}\text { Penyiapan lahan /lp } \\
\text { Batuan di permukaan } \\
\text { Singkapan batuan }\end{array}$ & $\begin{array}{l}0 \\
0\end{array}$ & $\begin{array}{l}0 \\
0\end{array}$ & $\begin{array}{l}0 \\
0\end{array}$ & $\begin{array}{l}0 \\
0\end{array}$ & $\begin{array}{l}0 \\
0\end{array}$ & $\begin{array}{l}0 \\
0\end{array}$ & $\begin{array}{l}0 \\
0\end{array}$ & $\begin{array}{l}0 \\
0\end{array}$ \\
\hline
\end{tabular}

Sumber: Data primer hasil analisis Laboratorium Riset Fakultas Pertanian USU (2016). 
Tabel 2. Rekapitulasi kesesuaian lahan untuk tanaman gambir(Uncaria gambier Roxb.).

\begin{tabular}{|c|c|c|c|}
\hline Land Unit & KLA & Perkiraan Usaha Perbaikan & KLP \\
\hline Unit lahan 1 & $\mathrm{~S}_{3}$-rc,nr & $\begin{array}{l}\text { - Pembuatan drainase } \\
\text { - Pengapuran } 4,14 \text { ton } \mathrm{CaCO}_{3} / \mathrm{ha}\end{array}$ & $\mathrm{S}_{3}$-rc \\
\hline Unit lahan 2 & $\mathrm{~S}_{3}-\mathrm{nr}$ & $\begin{array}{l}\text { - Pembuatan drainase } \\
\text { - Pengapuran 1,31 ton } \mathrm{CaCO}_{3} / \mathrm{ha}\end{array}$ & $\mathbf{S}_{2}-\mathbf{n r}$ \\
\hline Unit lahan 3 & $\mathrm{~S}_{3}-\mathrm{nr}$ & $\begin{array}{l}\text { - Pembuatan drainase } \\
\text { - Pengapuran } 7,76 \text { ton } \mathrm{CaCO}_{3} / \mathrm{ha}\end{array}$ & $\mathbf{S}_{2-} \mathbf{n r}$ \\
\hline Unit lahan 4 & $\mathrm{~S}_{3}-\mathrm{nr}$ & $\begin{array}{l}\text { - Pembuatan drainase } \\
\text { - Pengapuran 8,28 ton } \mathrm{CaCO}_{3} / \mathrm{ha}\end{array}$ & $\mathbf{S}_{2-} \mathbf{n r}$ \\
\hline Unit lahan 5 & $\mathrm{~S}_{3}-\mathrm{nr}$ & $\begin{array}{l}\text { - Pembuatan drainase } \\
\text { - Pengapuran 3,69 ton } \mathrm{CaCO}_{3} / \mathrm{ha}\end{array}$ & $\mathrm{S}_{2}-\mathrm{nr}$ \\
\hline Unit lahan 6 & $\mathrm{~S}_{3}-\mathrm{nr}$ & $\begin{array}{l}\text { - Pembuatan drainase } \\
\text { - Pengapuran 9,69 ton } \mathrm{CaCO}_{3} / \mathrm{ha}\end{array}$ & $\mathbf{S}_{2-} \mathbf{n r}$ \\
\hline Unit lahan 7 & $\mathrm{~S}_{3}-\mathrm{nr}$ & $\begin{array}{l}\text { - Pembuatan drainase } \\
\text { - Pengapuran 2,23 ton } \mathrm{CaCO}_{3} / \mathrm{ha}\end{array}$ & $\mathrm{S}_{2-} \mathbf{n r}$ \\
\hline Unit lahan 8 & $\mathrm{~S}_{3}-\mathrm{nr}$ & $\begin{array}{l}\text { - Pembuatan drainase } \\
\text { - Pengapuran 1,87 ton } \mathrm{CaCO}_{3} / \mathrm{ha} \\
\text { - Pemberian Bahan Organik 155,16 kg/ha atau 726,15 } \\
\text { kg/ha Pupuk Organik }\end{array}$ & $\mathbf{S}_{2-} \mathbf{n r}$ \\
\hline
\end{tabular}

Keterangan $:$ KLA $=$ Kesesuaian Lahan Aktual $;$ KLP $=$ Kesesuaian Lahan Potensial.

Tabel 3. Luas Kesesuaian lahan untuk tanaman gambir (Uncaria gambier Roxb.).

\begin{tabular}{cccrr}
\hline Unit Lahan & $\begin{array}{c}\text { Kesesuaian lahan } \\
\text { aktual }\end{array}$ & $\begin{array}{c}\text { Kesesuaian lahan } \\
\text { potensial }\end{array}$ & Luas (Ha) & Persentase (\%) \\
\hline 1 & $\mathrm{~S}_{3}-\mathrm{rc}, \mathrm{nr}$ & $\mathrm{S}_{3}-\mathrm{rc}$ & 74,46 & 2,06 \\
2 & $\mathrm{~S}_{3}-\mathrm{nr}$ & $\mathrm{S}_{2}-\mathrm{nr}$ & 1799,90 & 49,90 \\
3 & $\mathrm{~S}_{3}-\mathrm{nr}$ & $\mathrm{S}_{2}-\mathrm{nr}$ & 432,14 & 11,98 \\
4 & $\mathrm{~S}_{3}-\mathrm{nr}$ & $\mathrm{S}_{2}-\mathrm{nr}$ & 38,32 & 1,06 \\
5 & $\mathrm{~S}_{3}-\mathrm{nr}$ & $\mathrm{S}_{2}-\mathrm{nr}$ & 467,88 & 12,97 \\
6 & $\mathrm{~S}_{3}-\mathrm{nr}$ & $\mathrm{S}_{2}-\mathrm{nr}$ & 131,70 & 3,65 \\
7 & $\mathrm{~S}_{3}-\mathrm{nr}$ & $\mathrm{S}_{2}-\mathrm{nr}$ & 130,81 & 3,63 \\
8 & $\mathrm{~S}_{3}-\mathrm{nr}$ & $\mathrm{S}_{2}-\mathrm{nr}$ & 531,99 & 14,75 \\
\hline Total & & & 3607,20 & 100,00 \\
\hline
\end{tabular}

Sumber : Hasil Analisis GIS. 
Jurnal Tanah dan Sumberdaya Lahan Vol 7 No 1 : 7-14, 2020

e-ISSN:2549-9793, doi: 10.21776/ub.jts1.2020.007.1.2

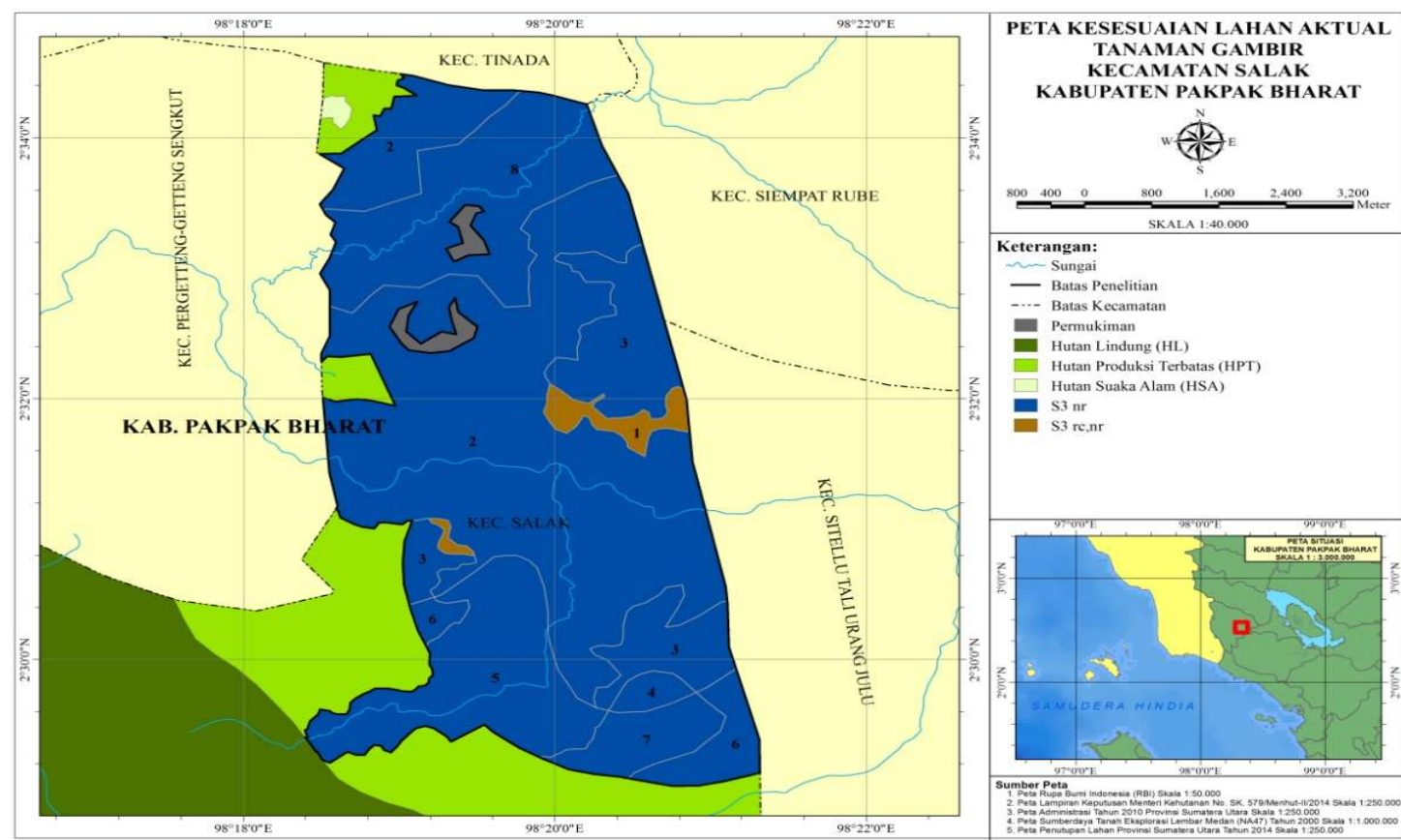

Gambar 3. Peta kesesuaian lahan aktual tanaman gambir (Uncaria gambier Roxb.) di lahan areal penggunaan lain Kecamatan Salak, Kabupaten Pakpak Bharat.
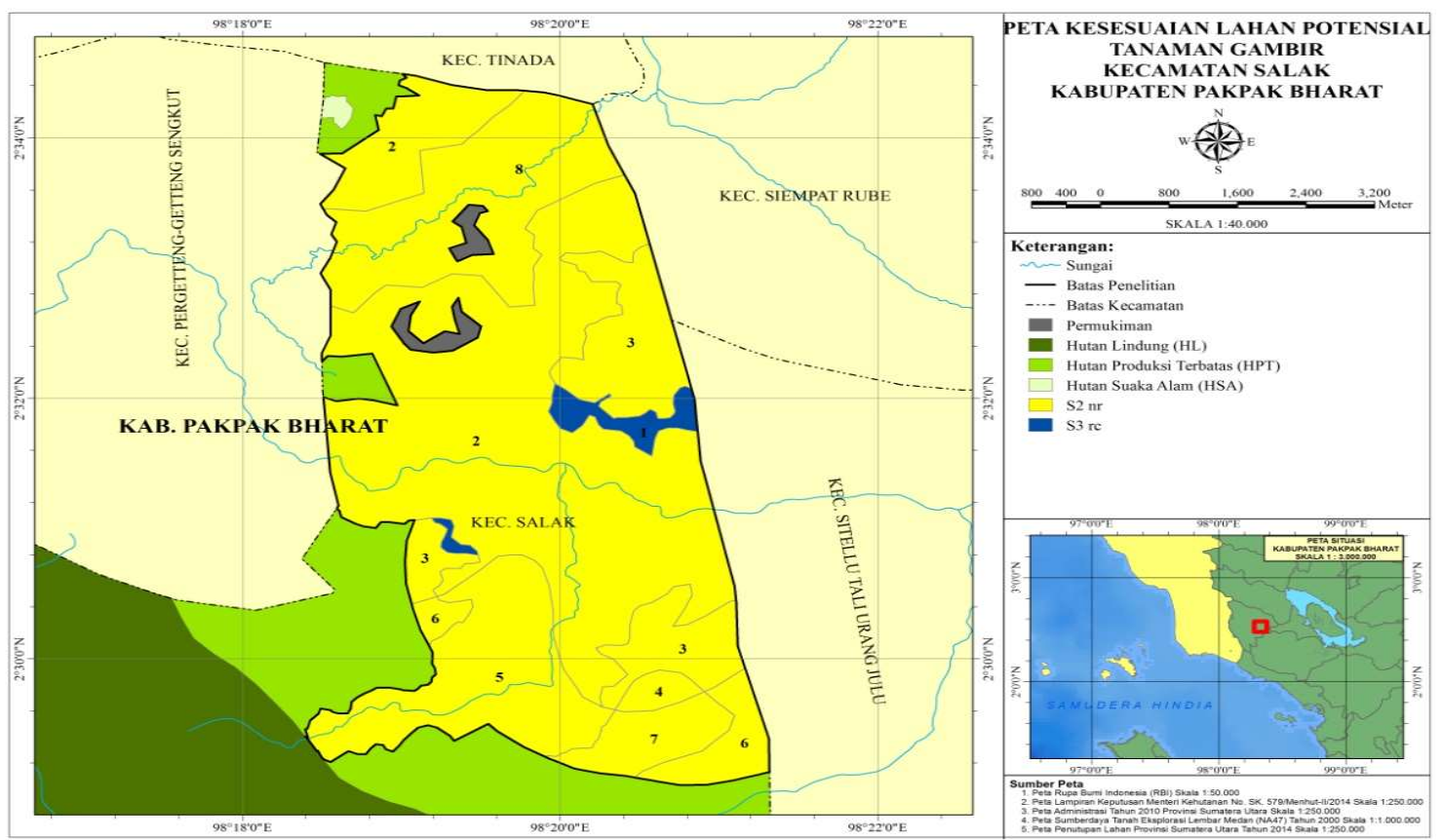

Gambar 4. Peta kesesuaian lahan potensial tanaman gambir (Uncaria gambier Roxb.) di lahan areal penggunaan Lain Kecamatan Salak, Kabupaten Pakpak Bharat. 


\section{Kesimpulan}

Faktor pembatas dan usaha perbaikan dari komoditi tanaman Tanaman Gambir (Uncaria gambier Roxb.) Faktor pembatas media perakaran (rc) dan retensi hara (nr). Usaha perbaikan yang dapat dilakukan yaitu pembuatan drainase dan pengapuran $\mathrm{CaCO}_{3}$.

\section{Daftar Pustaka}

BPTP Sumatera Utara, 2006. Pewilayahan Komoditas Pertanian Skala 1 : 50.000 di Kabupaten Pakpak Bharat. Kerjasama Pemerintahan Kabupaten Pakpak Bharat dengan Balai Pengkajian Teknologi Pertanian Sumatera Utara. 71 hal.

Dinas Pertanian dan Perkebunan Kabupaten Pakpak Bharat. 2012. Luas dan Produksi Tanaman Rakyat.Pemerintah Kabupaten Pakpak Bharat.

Djomantara, S. dan Rachmawati, N. 2000. Cara Pemilihan Lahan Berpotensi untuk Pengembangan Pertanian Suatu Wilayah. Buletin Teknik Pertanian 5: 41-42.

Elida, S. 2011. Strategi Pemasaran Gambir Kabupaten Kampar.Fakultas Pertanian Universitas Islam Riau. Jurnal Sosial Ekonomi Pembangunan. Tahun I. 3: 246-247.

Hardjowigeno, S. 2003. Ilmu Tanah. Akademika Pressindo. Jakarta.
Hermon, D. dan Khairani. 2009. Geografi Tanah. Yayasan Jihadul Khair Center. Padang

Hutapea, S. 1991. Evaluasi Metode Kesesuaian Lahan untuk Budidaya Kakao Lindak di Jawa Barat. Tesis. Program Pascasarjana, IPB, Bogor.

Mukhlis. 2007. Analisis Tanah dan Tanaman. USU Press, Medan.

Oldeman, L.R. 1975. The Agrodimatic Map of Java and Madura, Bogor. Contributions from the Central Research Institute for Agriculture.

Pemkab Pakpak Bharat (Pemerintah Kabupaten Pakpak Bharat). 2014. Pemerintah Kabupaten Pakpak Bharat. www.sumutprov.go.id. Diakses tanggal 11 April 2016.

Puslittan, Badan Litbangtan, Kementerian Pertanian Republik Indonesia, 1995. Evaluasi Kesesuaian Lahan.

Ritung, S., Nugrho, K., Mulyani, A. dan Suryani, E. 2011. Petunjuk Teknis Evaluasi Lahan Untuk Komoditas Pertanian. Balai Besar Penelitian dan Pengembangan Sumberdaya Lahan Pertanian, Puslitbangtanak, Badan Penelitian dan Pengembangan Pertanian. Bogor. hlm 159.

Sys, C., Van Ranst, E., Debaveye J. and Beernaert, F. 1993. Land Evaluation. Crop Requirements Part III. Agricultural Publication No.7. General Administration for Development Corp. 1050 Brussels- Belgium. 